\title{
Antioxidant potential and gap junction-mediated intercellular communication as early biological markers of mercuric chloride toxicity in the MDCK cell line
}

\author{
M.F. Aleo ${ }^{\text {a,* }}$, F. Morandini ${ }^{\text {a }}$, F. Bettoni ${ }^{\text {a }}$, S. Tanganellib ${ }^{\mathrm{b}}$, A. Vezzola ${ }^{\mathrm{a}}$, \\ R. Giuliani ${ }^{\mathrm{a}}$, N. Steimberg ${ }^{\mathrm{b}}$, P. Apostolic ${ }^{\mathrm{c}}$ G. Mazzoleni ${ }^{\mathrm{b}}$ \\ ${ }^{a}$ Department of Biochemical Sciences, Unit of Biochemistry, School of Medicine, University of Brescia, Via Valsabbina, 19, 25123 Brescia, Italy \\ ${ }^{\mathrm{b}}$ Unit of General Pathology and Immunology, School of Medicine, University of Brescia, Brescia, Italy \\ ${ }^{\mathrm{c}}$ Unit of Industrial Hygiene, School of Medicine, University of Brescia, Brescia, Italy
}

\begin{abstract}
In this study, the early nephrotoxic potential of mercuric chloride $\left(\mathrm{HgCl}_{2}\right)$ has been evaluated in vitro, by exposing a renalderived cell system, the tubular epithelial Madin-Darby canine kidney ( $\mathrm{MDCK}$ ) cell line, to the presence of increasing $\mathrm{HgCl}_{2}$ concentrations $(0.1-100 \mu \mathrm{M})$ for different periods of time (from 4 to $72 \mathrm{~h}$ ). As possible biological markers of the tubular-specific toxicity of $\mathrm{HgCl}_{2}$ in exposed-MDCK cultures we analysed: (i) critical biochemical parameters related to oxidative stress conditions and (ii) gap-junctional function (GJIC). $\mathrm{HgCl}_{2}$ cytotoxicity was evaluated by cell-density assay. The biochemical analysis of the pro-oxidant properties of the mercuric ion $\left(\mathrm{Hg}^{2+}\right)$ was performed by evaluating the effect of the metal salt on the antioxidant status of the MDCK cells. The cell glutathione (GSH) content and the activity of glutathione peroxidase (Gpx) and catalase (Cat), two enzymes engaged in the $\mathrm{H}_{2} \mathrm{O}_{2}$ degradation, were quantified. $\mathrm{HgCl}_{2}$ influence on $\mathrm{MDCK}$ GJIC was analysed by the microinjection/dye-transfer assay. $\mathrm{HgCl}_{2}-$ induced morphological changes in MDCK cells were also taken into account. Our results, proving that subcytotoxic $(0.1-10 \mu \mathrm{M}) \mathrm{HgCl}_{2}$ concentrations affect either the antioxidant defences of MDCK cells or their GJIC, indicate these critical functions as suitable biological targets of early mercury-induced tubular cell injury. (C) 2002 Elsevier Science Ltd. All rights reserved.
\end{abstract}

Keywords: Catalase; Gap junctions; Glutathione; Glutathione peroxidase; $\mathrm{HgCl}_{2}$; Intercellular communication; Kidney; MDCK cells; Mercury; Nephrotoxicity; Oxidative stress

\section{Introduction}

Mercury $(\mathrm{Hg})$ is one of the most diffused and hazardous organ-specific environmental contaminants (Agency for Toxic Substance and Disease Registry, 1999). It exists in a wide variety of physical and chemical forms, each with unique characteristics of target organ toxicity. Exposure to elemental $\mathrm{Hg}$ vapours $\left(\mathrm{Hg}^{0}\right)$ and to organic mercurials specifically affects the CNS (Hua et al., 1995; Oyama et

Abbreviations: Cat, catalase; FBS, foetal bovine serum; GJIC, gapjunctional function; Gpx, glutathione peroxidase (EC 1.11.1.9); GSH, glutathione; $\mathrm{Hg}$, mercury; $\mathrm{Hg}^{2+}$, mercuric ion; $\mathrm{HgCl}_{2}$, mercuric chloride; ICP-MS, inductively coupled plasma-mass spectrometry; MDCK, Madin-Darby canine kidney; MEM, minimum essential medium; NADPH, $\beta$-nicotinamide adenine dinucleotide phosphate, reduced form; PBS, phosphate buffered saline; ROS, reactive oxygen species.

* Corresponding author. Tel.: + 39-030-37-17-543; fax: + 39-03037-01-157.

E-mail address: aleo@med.unibs.it (M.F. Aleo). al., 1998), while the kidney is the primary target organ for inorganic $\mathrm{Hg}$ compounds (Tanaka et al., 1990; Zalups and Lash, 1994). Moreover, the oxidation state of the metal, in its different forms, plays a dominant role in the cellular transport, biological effects and toxicity of $\mathrm{Hg}$ (discussed by Divine et al., 1999). Among the inorganic mercuric $\left(\mathrm{Hg}^{2+}\right)$ salts, mercuric chloride $\left(\mathrm{HgCl}_{2}\right)$ has a typical nephrotoxic potential and it has been widely used (either in vitro or in vivo) for investigating the mechanisms of mercury-induced renal cell injury (see Zalups, 2000, for an extensive review). Findings from several studies suggest that direct/indirect mechanisms may be involved in the pathogenesis of $\mathrm{HgCl}_{2}$ nephrotoxic effects: biochemical damage of mitochondrial functions and calcium metabolism (Weinberg et al., 1982; Ambudkar et al., 1988; Chavez and Holguin, 1988), alterations of cytoskeleton integrity and cell membrane arrangement (Morrison and Pascoe, 1986; Elliget et al., 1991) were reported. Although significant advances have been made during the past decade, the molecular 
bases of the renal-specific $\mathrm{Hg}$ adverse effect have not been clarified up to now. More recent evidence suggests that the ability of mercuric ions $\left(\mathrm{Hg}^{2+}\right)$ to interact with the anionic form of proteins and glutathione sulfhydryl groups (R-S ${ }^{-}$) (Ballatori, 1991; Zalups, 2000) or to generate oxygen radicals (Sarafian and Verity, 1991; Lund et al., 1993; Nath et al., 1996) may play a major role. Thus the need for mechanistic studies is important in order to identify suitable biological markers for selective toxicological evaluation of mercurials.

Our study has been focused on the evaluation of early (and potentially reversible) nephrotoxic effects of $\mathrm{HgCl}_{2}$ in a renal-derived in vitro system, the epithelial MadinDarby canine kidney (MDCK) cell line. Since tubular epithelium represents the primary target of inorganic mercurials, this cell line was particularly suitable to our aim. This line has, in fact, well-known tubular differentiated properties, and for that reason it has been used extensively as a valuable in vitro model for studying tubular function and xenobiotic-induced nephrotoxicity (including that due to heavy metals) (Bohets et al., 1995; Prozialeck and Lamar, 1998).

As possible biological markers of the tubular-specific toxicity of $\mathrm{HgCl}_{2}$ in exposed MDCK cultures we analysed: (i) critical biochemical parameters related to oxidative stress conditions and (ii) gap-junctional function.

Antioxidant systems protect the cells against the adverse effects of reactive oxygen species (ROS). When these defences are depleted, cells are not efficiently preserved from oxidative damage (Valentine et al., 1998). The biochemical analysis of the pro-oxidant properties of $\mathrm{Hg}^{2+}$ was performed by evaluating the effect of the metal on the antioxidant status of MDCK cells. To this aim, the effect of $\mathrm{HgCl}_{2}$ treatment on: (a) the total intracellular glutathione (GSH) content and (b) the activity of glutathione peroxidase $(\mathrm{Gpx})$ and catalase (Cat) were quantified. GSH is, in fact, a non-protein thiol, playing a central role in the antioxidant defences of the cell, while Gpx and Cat are the two major enzymes engaged in $\mathrm{H}_{2} \mathrm{O}_{2}$ degradation.

Gap junction-mediated intercellular communication (GJIC) was chosen as a biological parameter in our study, since its evaluation represents one of the most promising and sensitive endpoints for the mechanistic evaluation of organ-specific toxicity (Swierenga and Yamasaki, 1992). GJIC is, in fact, a unique cell/tissue specific cellular function, with an unquestioned role in integrated regulation of growth, differentiation processes and functions of multicellular organisms and in tissue homeostatic control (Bruzzone et al., 1996). GJIC has, moreover, been proved to be specifically affected by various toxicants, including heavy metals (Loch-Caruso et al., 1991; Swierenga and Yamasaki, 1992), and via alterations similar to those supposed to be responsible for the cell-specific toxicity of mercuric ions (Saez et al., 1993).

\section{Materials and methods}

\subsection{Materials}

Cell culture chemicals were obtained from Gibco BRL (Life Technologies Italy s.r.l., Milan, Italy). Cell culture ware was purchased from Becton Dickinson \& Co. (Franklin Lake, NJ, USA). Analytical grade purity $\mathrm{HgCl}_{2}$ was obtained from Fluka (Milan, Italy). All other reagents and standards (analytical grade purity) were purchased from Sigma-Aldrich s.r.l. (Milan, Italy).

\subsection{Cell culture}

The Madin-Darby canine kidney (MDCK) cell line was kindly provided by Dr Nadia Losio (Istituto Zooprofilattico Sperimentale della Lombardia e dell'Emilia Romagna, Brescia, Italy). MDCK cells were routinely cultured in minimum essential medium (MEM) supplemented with $10 \%$ foetal bovine serum (FBS; Mascia Brunelli SpA, Milan, Italy) and containing 2 mm L-glutamine, antibiotic-antimycotic cocktail solution $(100 \mathrm{U} / \mathrm{ml}$ penicillin, $100 \mu \mathrm{g} / \mathrm{ml}$ streptomycin, $0.25 \mu \mathrm{g} / \mathrm{ml}$ fungizone) and $1 \mathrm{~mm}$ sodium pyruvate (complete cell growth medium). Cultures were maintained at $37{ }^{\circ} \mathrm{C}$ in a $5 \% \mathrm{CO}_{2}$ humidified atmosphere. The medium was changed twice a week and the confluent monolayers were regularly subcultured treating with $0.5 \%$ Trypsin- $0.2 \%$ ethylenediaminetetraacetic acid (EDTA) at $37^{\circ} \mathrm{C}$ for $15 \mathrm{~min}$.

\section{3. $\mathrm{HgCl}_{2}$ treatment and $\mathrm{Hg}^{2+}$ quantification}

MDCK cell cultures in logarithmic growing phase were exposed for different periods of time (from 4 to $72 \mathrm{~h}$ ) to $\mathrm{HgCl}_{2}$, ranging from 0.1 to $100 \mu \mathrm{M}$ concentration. The inorganic salt was accurately dissolved in milli-Q water to prepare a $100 \mathrm{~mm}$ stock solution; then, aliquots of this stock solution were diluted in complete cell growth medium, up to the final $\mathrm{HgCl}_{2}$ concentration used for each treatment. Complete solubilisation of the salt in the culture media was verified by quantification of mercuric ions by Inductively Coupled Plasma-Mass Spectrometry (ICP-MS), using a Perkin Elmer ELAN 5000.

In order to avoid any possible interference due to the release of metal ions (e.g. lead) from the glassware, all the experimental procedures (preparation and stocking of solutions, cell culturing, etc.) were performed by using biologically inert plastic materials.

\subsection{Cytotoxicity study: cell proliferation and cell viability assays}

For cell proliferation assay, $0.6 \times 10^{6}$ cells were seeded onto $100-\mathrm{mm}$ plastic tissue culture plates. $24 \mathrm{~h}$ after the plating, the growth medium was removed and MDCK cells received freshly prepared media containing $\mathrm{HgCl}_{2}$ 
ranging from 0.1 to $100 \mu \mathrm{M}$ concentration. After 4, 24, 48 or $72 \mathrm{~h}$ of exposure to the mercuric salt, monolayer cultures were treated with Trypsin-EDTA solution and cell number determined using an hemocytometer. Cell viability was assessed, in the same experimental conditions, by using the Vybrant Apoptosis Assay kit \#2 (Molecular Probes Incorporation, Eugene, OR, USA), followed by flow cytometric analysis (FACSTAR, Becton-Dickinson).

\subsection{Determination of total glutathione content in MDCK cells}

MDCK cells in logarithmic growing phase (see cell proliferation assay) were exposed for 24,48 or $72 \mathrm{~h}$ to increasing concentrations $(0.1-50 \mu \mathrm{M})$ of $\mathrm{HgCl}_{2}$. Total intracellular glutathione (reduced glutathione and its oxidised forms) (GSH) was quantified in the acid fraction of cell extracts by the enzymatic method of Anderson (1985). Briefly, monolayers of $\mathrm{HgCl}_{2}$-treated and untreated cells (used as controls) were rinsed twice with cold phosphate buffered saline and then deproteinised with aliquots of cold sulfosalicylic acid $(5 \%, \mathrm{w} / \mathrm{v})$ solution, in order to obtain the same ratio volume/cell number for each sample. After $20 \mathrm{~min}$ at $4{ }^{\circ} \mathrm{C}$, cells were harvested by scraping and the extracts centrifuged at $10,000 \mathrm{~g}$ for $15 \mathrm{~min}$. The supernatants (acid fraction) were immediately analysed by a Jasco V-530 spectrophotometer (Cremella, LC, Italy). The intracellular amount of GSH was expressed as nmol/ $10^{6}$ cells, using a GSH standard calibration curve. Two single determinations of each sample were executed.

\subsection{Enzymatic assays (glutathione peroxidase and catalase)}

The activity of the antioxidant enzymes glutathione peroxidase (Gpx) and catalase (Cat) was determined in MDCK cell homogenates after exposure to increasing $\mathrm{HgCl}_{2}$ concentrations $(0.1-50 \mu \mathrm{M})$ for different periods of time $(4,24,48$ or $72 \mathrm{~h})$. All steps were performed at $4{ }^{\circ} \mathrm{C}$. The growth media were withdrawn and, after extensive washing, cells were harvested by scraping and then homogenised by pipetting in the specific enzyme assay buffer. Cell homogenates were then centrifuged at 10,000 $g$ for $15 \mathrm{~min}$ and the supernatants employed for the quantification of total protein content and for measuring the enzymatic activities.

Gpx activity was evaluated, at $30{ }^{\circ} \mathrm{C}$, by the colorimetric BIOXYTECH GPX-340 ${ }^{\mathrm{TM}}$ assay system (OXIS International, Inc., Portland, OR, USA) following NADPH oxidation at $340 \mathrm{~nm}$ in $50 \mathrm{~mm}$ Tris- $\mathrm{HCl}$ buffer ( $\mathrm{pH}$ 7.6) containing $5 \mathrm{~mm}$ EDTA and $1 \mathrm{~mm} 2$-mercaptoethanol. The enzyme specific activity was expressed as $\mathrm{nmol} / \mathrm{min} / \mathrm{mg}$ of protein.

Cat activity was determined by measuring the decrease in absorption at $240 \mathrm{~nm}$ wavelength in $50 \mathrm{~mm}$
$\mathrm{Na} / \mathrm{K}$ phosphate buffer ( $\mathrm{pH} 7.0$ ), $1 \%$ Triton $\mathrm{X}-100$ and $10 \mathrm{~mm} \mathrm{H}_{2} \mathrm{O}_{2}$ (Aebi, 1984). The pseudo-first order reaction constant $(k)$ of the decrease in $\mathrm{H}_{2} \mathrm{O}_{2}$ absorption/s at $25{ }^{\circ} \mathrm{C}$ was determined and the enzyme specific activity was expressed as $k / \mathrm{mg}$ of proteins.

Protein content was estimated according to Bradford (1976) using the Coomassie Protein Assay reagent (Pierce, Rockford, IL, USA) and bovine serum albumin as standard.

\subsection{Influence of $\mathrm{HgCl}_{2}$ on the GJIC capacity and morphology of MDCK cells}

MDCK cells were tested for their capacity to establish functional gap junctions (gjs) by the use of the microinjection/dye-transfer assay (Mazzoleni et al., 1994). For reproducing the same cell density conditions used in all the other experimental procedures, $2.0 \times 10^{5} \mathrm{MDCK}$ cells were seeded onto $60-\mathrm{mm}$ petri dishes. $24 \mathrm{~h}$ after plating, cell cultures were exposed for $4 \mathrm{~h}$ (dye-transfer assay) or for 24-72 h (morphological study) to increasing concentrations of $\mathrm{HgCl}_{2}(0.1-50 \mu \mathrm{M})$. For the dyetransfer assay, single cells within the monolayers (three separate dishes/experimental point) were microinjected with a $10 \%(\mathrm{w} / \mathrm{v})$ solution of the gap-junction permeant fluorescent tracer Lucifer Yellow $\mathrm{CH}$ in $0.33 \mathrm{~m}$ lithium chloride. Microinjections were performed by glass capillary needles (Clark Electromedical Instruments, Edenbridge, UK) prepared with an automatic puller (Narishige, Tokyo, Japan) and driven by a Narishige micromanipulator (SYF II) linked to an Olympus IMT2 fluorescence microscope. The fluorescent dye was injected into single cells under nitrogen pressure using an Eppendorf microinjector (Hamburg, Germany). Five minutes after the last injection, the cells were fixed with $4 \%$ paraformaldehyde in PBS and their dye-transfer capacity was evaluated. The extent of the gap junctionmediated intercellular communication (GJIC) was then quantified by counting the number of fluorescent cells surrounding the microinjected ones (no. of dye-coupled cells/injection). For the precise quantification of the GJIC competence of the cultures, at least 25 independent microinjection trials/dish were taken into account. Fluorescence and phase-contrast images of untreated and $\mathrm{HgCl}_{2}$-treated monolayers were analysed by an Axiovert S100 inverted microscope (Zeiss, Milan, Italy) equipped with a Semican 12-bit cooled imaging camera (PCO-CDD Imaging). Microscopic images were captured with Image ProPlus software (4.0 for Windows) (Media Cybernetics, Silver Spring, MD, USA).

\subsection{Statistics}

Statistical analysis was applied to the results obtained in the study of the biochemical parameters related to oxidative stress conditions (GSH, Gpx and Cat activity). 
Data, normalised as percentage of control values, were transformed into their logarithmic $(\log )$ values before statistical analysis. To multiple means was applied the analysis of variance followed by Fisher's protected least significant difference test. Statements of significance (in the text) were based on a $p$ value less than 0.05 .

\section{Results}

\section{1. $\mathrm{Hg}^{2+}$ quantification in complete media solutions}

In order to precisely define our experimental conditions ( $\mathrm{HgCl}_{2}$ solubility and $\mathrm{Hg}^{2+}$ bioavailability), the quantification of $\mathrm{Hg}^{2+}$ in the complete culture media used for each treatment has been performed. The ICP-MS analysis of $\mathrm{HgCl}_{2}$-containing media $(0.1-50 \mu \mathrm{M})$ demonstrated a good relation between the expected theoretical $\mathrm{Hg}^{2+}$ concentration and the real concentration of the dissolved (bioavailable) mercuric ion, the mean value $( \pm$ S.D.) of the ratio of real vs theoretical $\mathrm{Hg}^{2+}$ concentration resulting equal to $1.10 \pm 0.14$.

\subsection{Effects of $\mathrm{HgCl}_{2}$ on $\mathrm{MDCK}$ cell viability, proliferation and morphology}

The direct $\mathrm{HgCl}_{2}$ influence on $\mathrm{MDCK}$ cell viability and growth rate was assessed as described above. Cell proliferation assay was preferred to others (MTT and NR tests) since, in our hands, it was demonstrated to be the most sensitive and reproducible. For example, while in the case of $72 \mathrm{~h}$ treatment with $50 \mu \mathrm{M} \mathrm{HgCl}_{2}$ cell proliferation assay showed a significant toxic effect of the mercuric salt $(65 \%$ reduction of MDCK cell density in respect to untreated controls), in the same experimental conditions the toxic effect measured by MTT and NR assays was respectively 2.6 and 4.0 times lower. Cell cultures in logarithmic growing phase were exposed up to $72 \mathrm{~h}$ to $\mathrm{HgCl}_{2}$ at concentrations ranging from 0.1 to $100 \mu \mathrm{M}$. The mercuric salt was found to affect MDCK cell density by two different ways: (i) a direct action on cellular viability and (ii) an influence on MDCK cell growth rate. Both effects were dose and time related. At $100 \mu \mathrm{M}$ concentration, $\mathrm{HgCl}_{2}$ caused cell death (cytotoxic effect): no viable cells were, in fact, detected already after a $24 \mathrm{~h}$ exposure to the salt. Administered at concentrations of up to $50 \mu \mathrm{M}, \mathrm{HgCl}_{2}$ reduced MDCK cell density in respect to untreated controls in a dose- and time-related manner (Fig. 1). The $\mathrm{HgCl}_{2}$ effect on MDCK cell density (decrease) was maximal already after $24 \mathrm{~h}$ from the beginning of the treatments: from $90 \%(0.1 \mu \mathrm{M})$ to $20 \%(50 \mu \mathrm{M})$ in respect to control values and it did not change significantly during the following $48 \mathrm{~h}$, as expressed by the $\operatorname{IC}_{50}$ values $(34,33$ and $31 \mu \mathrm{M}$ at respectively 24,48 and $72 \mathrm{~h}$ from the beginning of the treatment).

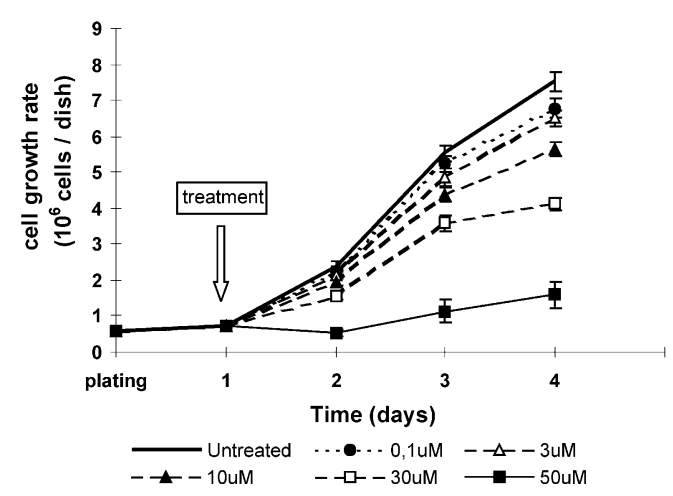

Fig. 1. Time-dependent effect of different $\mathrm{HgCl}_{2}$ concentrations on MDCK cell growth rate. Cell density was evaluated after exposing the cells to increasing concentrations of the mercuric salt for 24,48 or 72 h. Values (means \pm S.E.M.) are representative of data obtained in seven independent experiments, each performed in triplicate $(n=21)$.

Fig. 2 shows how, independently from the duration of each treatment, the dose-dependent inhibitory effect of $\mathrm{HgCl}_{2}$ on MDCK growth rate was quite similar for $\mathrm{HgCl}_{2}$ concentrations up to $10 \mu \mathrm{M}$ (linear behaviour), while for $\mathrm{HgCl}_{2}$ concentrations greater than $10 \mu \mathrm{M}$ this inhibitory effect was increasingly greater, also in relation to the treatment length (exponential behaviour).

"Vybrant" assay substantially confirmed the results obtained by the proliferation assay. No differences in cell viability were, in fact, found comparing $\mathrm{HgCl}_{2}$-treated (up to $30 \mu \mathrm{M}$ ) and untreated MDCK cells. On that basis, $10 \mu \mathrm{M}$ was considered, in our conditions, the highest non-cytotoxic concentration of mercuric chloride; this was taken into account for the following experimental procedures.

The morphological analysis (light microscopy) showed that, even at non-cytotoxic concentrations (up to $10 \mu \mathrm{M}), \mathrm{HgCl}_{2}$ induced relevant morphological alterations in MDCK-treated cells (Plate 1). This effect was also dose and time related, being more pronounced for the highest $\mathrm{HgCl}_{2}$ concentrations and for the most prolonged treatments. Exposed to the mercuric salt, MDCK cells progressively lose their characteristic and

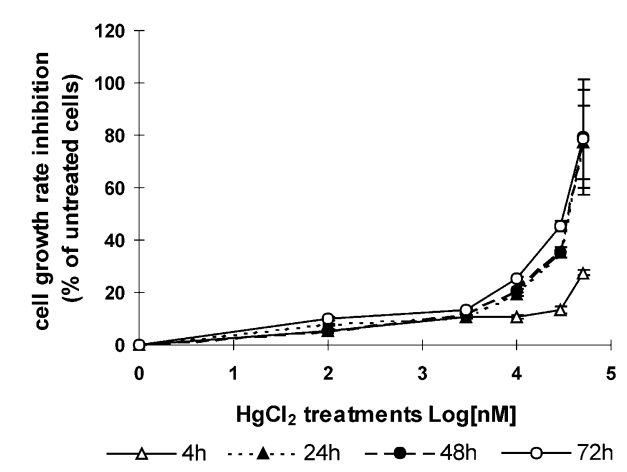

Fig. 2. Dose-dependent effect of $\mathrm{HgCl}_{2}$ on MDCK growth rate in respect to the treatment length. Growth rate values, expressed as percentage of those of untreated cells, are plotted against the Log-nanomolar concentrations of the mercuric salt, and represent the means \pm S.E.M. of 21 independent determinations. 


\section{Untreated}

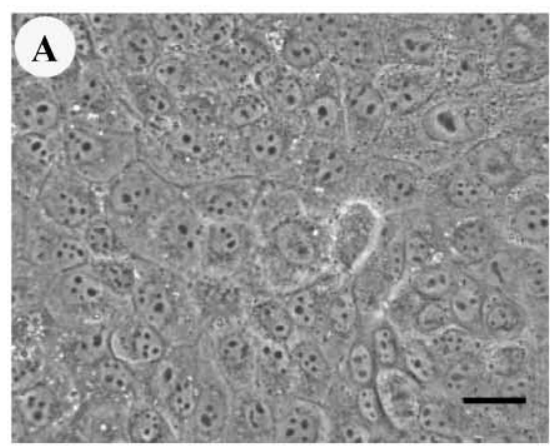

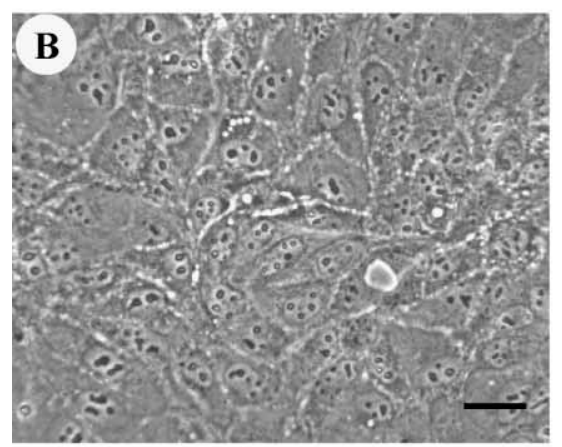

$0.1 \mu \mathrm{M} \mathrm{HgCl}_{2}$

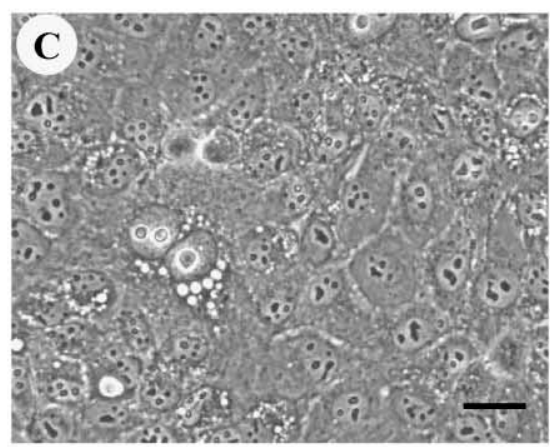

$1 \mu \mathrm{M} \mathrm{HgCl}_{2}$

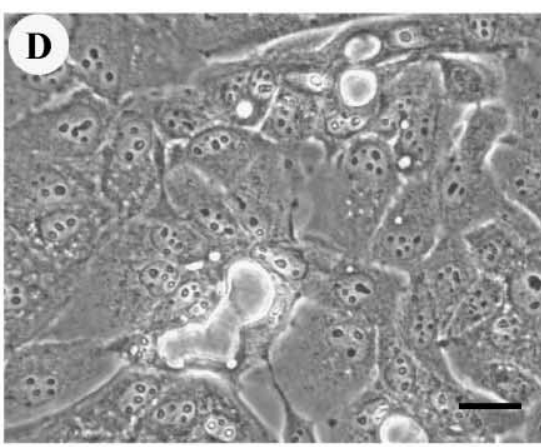

$10 \mu \mathrm{M} \mathrm{HgCl}_{2}$

Plate 1. Influence of $\mathrm{HgCl}_{2}$ on MDCK cell morphology. Phase-contrast microscopic images were taken on MCDK cells grown for $48 \mathrm{~h}$ in the presence of 10\% FBS-MEM (A) or in FBS-MEM medium supplemented with increasing, non-cytotoxic $\mathrm{HgCl}_{2}$ concentrations $(\mathrm{B}, \mathrm{C}, \mathrm{D})$. Bars $=25$ $\mu \mathrm{m}$. Note the morphological changes of $\mathrm{HgCl}_{2}$-exposed MDCK cells and the progressive (B-D) appearance of intracellular vesicles.

regular epithelial shape, becoming more voluminous and heterogeneous in their dimension. The presence of differently sized intra-cytoplasmic vesicles (the number and dimension of which were related to the mercuric salt concentration and/or to the length of the treatment) was also a peculiar aspect of treated cells. Interestingly, the presence of such intracellular vesicles was also coupled to the presence of a sort of extracellular deposit, as if the metal should induce an increased excretory activity in this cell line (discussed later).

\section{3. $\mathrm{HgCl}_{2}$ influence of the anti-oxidant status of MDCK cells}

\subsubsection{Total cellular glutathione}

As shown in Fig. 3, the total GSH content of untreated MDCK cells varied as a function of cell growth rate; it was maximum after cell seeding and during the first $24 \mathrm{~h}$ of culture (latency phase of growth), then it decreased, reaching the minimum value (more than four times less) on day 3 of culture. Then, on day 4 of culture, the total GSH cell content started to increase again.

As illustrated in Fig. 4, the GSH content of MDCK cells treated for 48 and $72 \mathrm{~h}$ with 0.1 and $3 \mu \mathrm{M} \mathrm{HgCl} 2$ slightly increased (about 20\%) in respect to control values, while, in cells exposed to the mercuric salt at 10

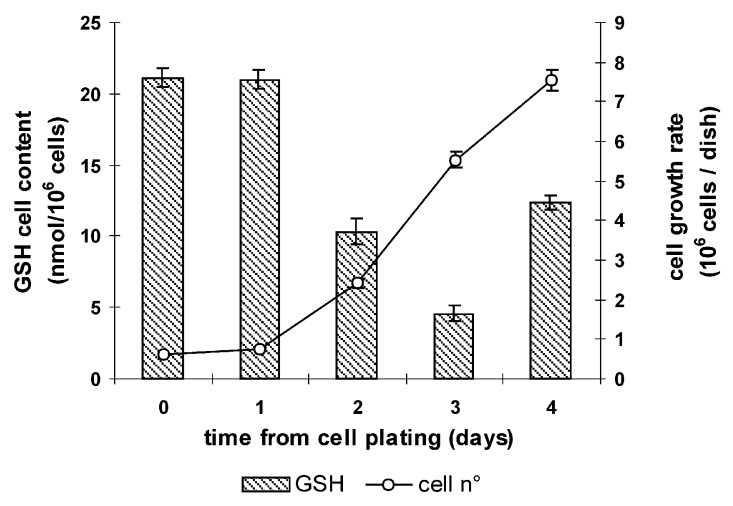

Fig. 3. Total GSH content of untreated MDCK cells in growing phase. The time course of the GSH amount ( $\mathrm{nmol} / 10^{6}$ cells) is related to the variations density of cell (cell number/dish). Values represent the means \pm S.E.M of five different experiments where the GSH determinations were performed in duplicate $(n=10)$.

$\mu \mathrm{M}$ concentration, that increase was significantly higher and already evident starting from the first $24 \mathrm{~h}$ from the beginning of the treatment. In this case, the quantity of cellular GSH reached its maximal value $(200 \%$ increase in respect to untreated controls) after a $48 \mathrm{~h}$ of treatment. The GSH amount detected in extracts of $30 \mu \mathrm{M} \mathrm{HgCl}_{2-}$ treated cells was lower (or similar) to that obtained in the untreated controls. This last result should be considered cautiously, since we observed that the determination of 


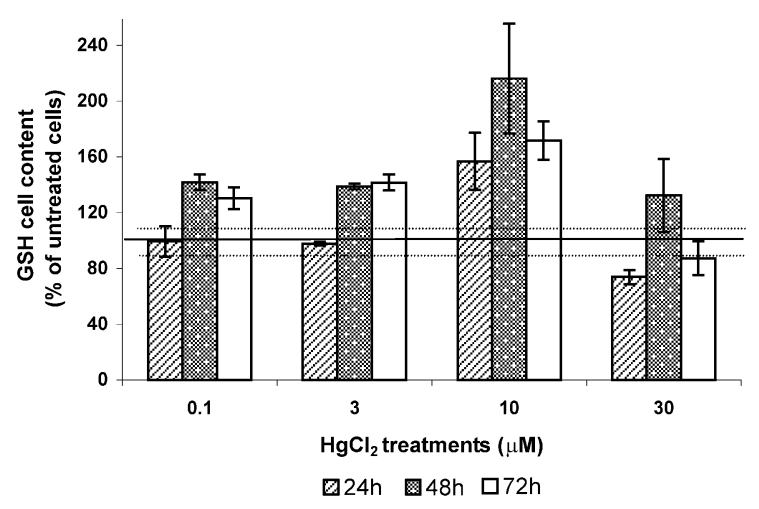

Fig. 4. Effect of different $\mathrm{HgCl}_{2}$ concentrations on the total cellular glutathione (GSH) content. MDCK cells were exposed to different concentrations of the mercuric salt for 24-72 h. GSH quantity (nmol/ $10^{6}$ cells) is expressed as percentage of that of untreated controls. In the case of the $50 \mu \mathrm{M}-\mathrm{HgCl}_{2}$ treatment GSH cell content was under the limit of detection and, therefore, values are not reported. Data points represent the means \pm S.E.M of three different experiments where the GSH determinations were performed in duplicate $(n=6)$.
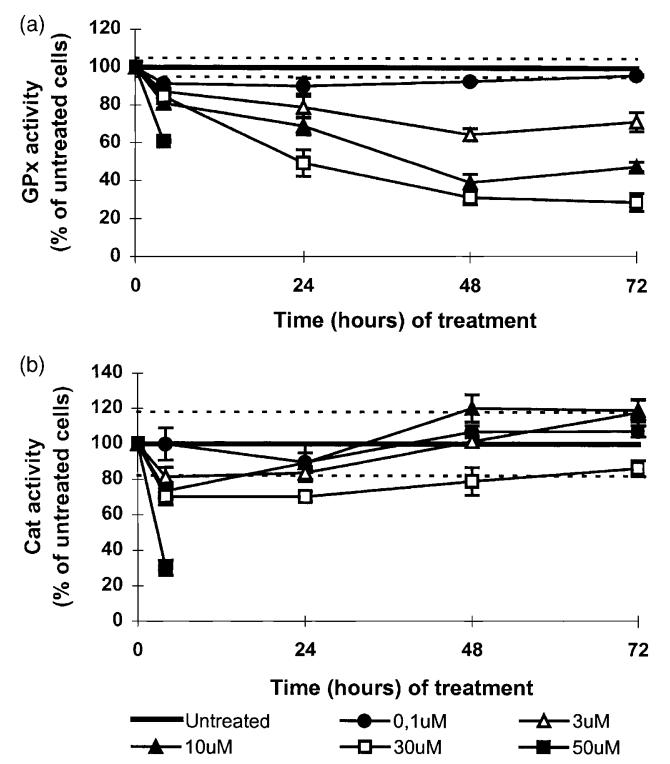

Fig. 5. Effect of $\mathrm{HgCl}_{2}$ on $\mathrm{Gpx}$ (a) and Cat (b) activity. The enzymatic activities were both measured on MDCK cells exposed to the mercuric salt (for 4-72 h) and values are expressed as $\mathrm{nmol} / \mathrm{min} / \mathrm{mg}$ of proteins (a) and as $k / \mathrm{mg}$ of proteins (b). Data were normalised as percentage of the basal activity of untreated cells. For each enzyme, the values represent the means \pm S.E.M of three different experiments where the

total cell GSH was influenced by the presence of high intracellular $\mathrm{Hg}^{2+}$ concentrations.

\subsubsection{Glutathione peroxidase and catalase activity}

Results in Fig. 5(a) show a progressive and significant decrease of Gpx activity when MDCK cells were exposed to the mercurial salt. This inhibitory effect, dose- and time related, was evident already after $4 \mathrm{~h}$ from the beginning of the treatment with $\mathrm{HgCl}_{2}$ at all the concentrations tested, but it was significantly marked in the case of the $50 \mu \mathrm{MgCl}_{2}$ treatment; in this case, in fact, the inhibition of Gpx activity reached the $40 \%$ of the value of untreated controls. The mercuric salt directly affected the Gpx activity, since the binding of $\mathrm{Hg}^{2+}$ with the GSH (substrate) added in the assay media did not significantly modify the results. The analysis of $\mathrm{HgCl}_{2}$ influence on MDCK cells Cat activity gave different results. Fig. 5(b) shows that when MDCK cells were exposed to $\mathrm{HgCl}_{2}$ concentrations up to $10 \mu \mathrm{M}$, neither dose- nor time-dependent modification of Cat activity was detected, whereas at higher concentrations the mercuric salt inhibited the enzyme activity from $20 \%\left(30 \mu \mathrm{M} \mathrm{HgCl}_{2}\right)$ to $70 \%\left(50 \mu \mathrm{M} \mathrm{HgCl}_{2}\right)$, in respect to untreated controls.

\subsection{Influence of $\mathrm{HgCl}_{2}$ on $\mathrm{MDCK}$ junctional coupling}

MDCK cells are well-differentiated tubular-derived epithelial cells, endowed with a basal relatively low communication capacity and, as previously reported, they are very sensitive to the effect of renal toxicants. To avoid non-specific effects on the cell dye-transfer capacity, chemicals to be tested must be added to cell cultures at non-cytotoxic concentrations (i.e. at concentrations that do not significantly impair cell growth rate). $\mathrm{HgCl}_{2}$ was then examined for its capacity to interfere with MDCK cells GJIC. MDCK monolayers, cultured at the same density conditions used for all the experimental procedures described above, were exposed for $4 \mathrm{~h}$ to the presence of increasing concentrations of $\mathrm{HgCl}_{2}(0.1-50$ $\mu \mathrm{M})$. These treatment conditions were not cytotoxic and they did not significantly modify cell density (cell density, by itself, influences the basal level of GJIC). In Table 1, our results show that at $4 \mathrm{~h}$ of treatment with 0.1-10 $\mu \mathrm{M} \mathrm{HgCl}_{2}$ (proved to be non-cytotoxic up to $72 \mathrm{~h}$ of treatment) significantly affected MDCK cells junctional coupling (more than 50\% inhibition of GJIC in respect to untreated controls). Tested at $50 \mu \mathrm{M}$ concentration, $\mathrm{HgCl}_{2}$ almost completely abolished the dye-transfer capacity of MDCK cells (about $95 \%$ inhibition). At this last concentration cell density was about $80 \%$ that of untreated cultures.

\section{Discussion}

Owing to industrialisation and changes occurring in the environment during the last century, human exposure to mercury $(\mathrm{Hg})$ became ubiquitous and the precise evaluation of $\mathrm{Hg}$-specific toxicological risk a problem of public health policy. All forms of mercury cause toxic effects in a number of organs and tissues, related to various factors (chemical $\mathrm{Hg}$ forms, level, duration and route of exposure). Kidney is the primary target of inorganic $\mathrm{Hg}$ toxicity, the tubular epithelium being the most vulnerable structure of the nephron (Agency for 
Table 1

Effect of $\mathrm{HgCl}_{2}$ on MDCK gap-junctional intercellular communication (GJIC)

\begin{tabular}{lll}
\hline Treatment & $\begin{array}{l}\text { No. of dye-coupled } \\
\text { cells/microinjection }\end{array}$ & $\begin{array}{l}\text { MDCK junctional } \\
\text { coupling (\% of } \\
\text { untreated controls) }\end{array}$ \\
\hline Untreated control & $5.25 \pm 0.72(n=60)$ & $100 \pm 14.0$ \\
$0.1 \mu \mathrm{M} \mathrm{Hel}_{2}$ & $2.22 \pm 0.33(n=70)$ & $42 \pm 6.0$ \\
$1.0 \mu \mathrm{M} \mathrm{HgCl}$ & $2.27 \pm 0.30(n=103)$ & $43 \pm 7.5$ \\
$10 \mu \mathrm{M} \mathrm{HgCl}_{2}$ & $2.51 \pm 0.37(n=101)$ & $48 \pm 7.0$ \\
$50 \mu \mathrm{M} \mathrm{HgCl}_{2}$ & $0.29 \pm 0.11(n=96)$ & $6 \pm 2.0$ \\
\hline
\end{tabular}

MDCK cells were exposed for $4 \mathrm{~h}$ to increasing $\mathrm{HgCl}_{2}$ concentrations. Their communication capacity (GJIC) was quantified by counting the number of fluorescent cells surrounding the microinjected ones (number of dye-coupled cells/microinjection). Values represent the mean$\mathrm{s} \pm$ S.E.M. from a single experiment performed in triplicate. $n=$ number of independent microinjections.

Toxic Substances and Disease Registry, 1999). During the past two decades, mercuric chloride $\left(\mathrm{HgCl}_{2}\right)$ has been widely used, either in vitro or in vivo, as a model for investigating the mechanism(s) of $\mathrm{Hg}$-induced nephrotoxicity. Nevertheless, the results obtained are still not conclusive, even if findings from several studies strongly suggest the induction of oxidative stress as an important cause of $\mathrm{Hg}$-induced renal cell injury (reviewed by Zalups, 2000).

In the present study, the tubular-derived MDCK cell line was tested as a suitable in vitro model for the mechanistic study of the early nephrotoxic potential of $\mathrm{HgCl}_{2}$. To this aim, MDCK sensitivity to the mercuric salt was investigated and the influence of subcytotoxic $\mathrm{HgCl}_{2}$ concentrations evaluated either on the cellular defences against oxidative stress (GSH cell content, Gpx and Cat activities) or on the GJIC.

In our experimental conditions, cell density assay was found to be a reliable and sensitive index of $\mathrm{HgCl}_{2}$ toxicity, $10 \mu \mathrm{M}$ being the highest non-cytotoxic concentration of the mercuric salt for the MDCK cell line. The sensitivity of our model to the mercuric ions was also confirmed by the $\mathrm{IC}_{50}$ values, which were comparable to those obtained with other renal-derived in vitro models (Aleo et al., 1992).

Concerning the analysis of $\mathrm{HgCl}_{2}$ influence on the antioxidant defences of MDCK cells, the quantification of total intracellular GSH, as well as the determination of the enzymatic activity of Gpx and Cat, provided evidences that confirmed the ability of the metal in predisposing cells to oxidative damage.

GSH is the major non-protein thiol, involved in a number of important physiological processes; it works as an intracellular redox buffer and is responsible of critical steps in the metabolism and detoxification of various substances, including metallic cations (Ballatori, 1994). Mercuric ions $\left(\mathrm{Hg}^{2+}\right)$ usually form $1: 2\left(\mathrm{Hg}^{2+}: \mathrm{S}^{-}\right)$complexes with thiols (GSH, proteins). This reaction occurs spontaneously (non-enzymatically) and is reversible, but, with its equilibrium shifted towards the formation of the mercury-thiols complexes, they represent the predominant $\mathrm{Hg}^{2+}$ species (Ballatori, 1994). The high affinity of mercuric ions for binding to thiols naturally has suggested that the depletion of intracellular thiols (especially GSH) may, directly or indirectly, cause tubular cell damage (Zalups, 2000).

Measured just after the seeding, the intracellular GSH content of MDCK cells was approximately equal to 20 $\mathrm{nmol} / 10^{6}$ cells. The biphasic time course of the GSH levels observed during the logarithmic phase of their growth could be considered as a consequence of an early redistribution of the "old" tripeptide within the "new" MDCK cell population. When cells started to synthesise the thiol again, its concentration gradually increased.

Intracellular GSH significantly increased when MDCK cultures were exposed to the presence of $\mathrm{HgCl}_{2}$. This event, dose and time related, could depend on an early activation of the GSH synthesis. This may, in fact, represent the mechanism by which the cells, "neutralising" the free mercuric ions, are able to reduce their toxic effect (Miura and Clarkson, 1993; Bohets et al., 1995). On the other hand, due to the high affinity of $\mathrm{Hg}^{2+}$ for the thiol, the formation of $\mathrm{Hg}-\mathrm{GSH}$ complexes could strongly decrease the intracellular concentration of the free tripeptide, thus affecting (reducing) the total cell redox potential (see, for example, Zalups and Lash, 1990; Lash and Zalups, 1992). Our results are very consistent with this hypothesis and may, in addition, partially explain what was seen in the case of $\mathrm{HgCl}_{2}$-induced variations of Gpx activity. Theoretically, a decrease in the activity of antioxidant enzymes would be expected to enhance the susceptibility of cells to oxidative injury.

We demonstrated that in MDCK cells $\mathrm{HgCl}_{2}$ significantly inhibits Gpx and, to a lesser extent, also Cat activity. This evidence, together with the $\mathrm{HgCl}_{2}$-induced depletion of intracellular free glutatione, suggests that in the presence of the mercuric salt, the antioxidant potential of MDCK is reduced.

Cellular fractionation studies demonstrated that, following acute and chronic in vivo exposure to $\mathrm{HgCl}_{2}$, mercury gains entry in tubular cells and distributes throughout all intracellular pools, nuclear and cytosolic fractions included (Madsen and Hansen, 1980). Even if the mechanisms involved in the urinary excretion of mercury are largely unknown, it has been suggested that a large amount of mercury in the urine probably originated from cellular stores, also including the possibility of an active luminal secretion of accumulated mercury by tubular cells (discussed by Zalups, 2000). This may explain some of the morphological effects we observed in $\mathrm{HgCl}_{2}$-exposed MDCK tubular cells.

When tested for their capacity to produce early effects of MDCK junctional function, subcytotoxic doses of $\mathrm{HgCl}_{2}(0.1,1.0$ and $10 \mu \mathrm{M})$ were proved to significantly 
affect cell coupling (the residual GJIC capacity was lower than $50 \%$ in respect of controls). Moreover, this effect was unrelated to the extracellular concentration of the mercuric salt. At $50 \mu \mathrm{m}$ concentration, the inhibitory effect of $\mathrm{HgCl}_{2}$ on MDCK cells GJIC was maximal (residual GJIC capacity lower than $10 \%$ in respect of controls). This suggests that, as observed in the case of $\mathrm{HgCl}_{2}$ influence on MDCK cell density and GSH, a sort of threshold effect should exist also for the $\mathrm{HgCl}_{2}$ effect on MDCK GJIC. The $\mathrm{HgCl}_{2}$-induced inhibitory effect on MDCK cell coupling should be considered specific since, in our experimental conditions, it occurs also at very low, non-cytotoxic $\mathrm{HgCl}_{2}$ concentration $(0.1 \mu \mathrm{M})$.

The sensitivity of MDCK cell junctional function to the mercuric salt (in respect of that reported for other cell types) (see, for example, Loch-Caruso et al., 1991) may be due to the tubular differentiated features of this cell line. As in the case of renal tubular epithelial cells in vivo (Guo et al., 1998), MDCK cells express, as major component of their junctional channels, connexin 43 protein (Berthoud et al., 1992). This consideration is important since the GJIC response to chemicals has been proved to be strictly connexin-specific (Mazzoleni et al., 1996). The specificity of the $\mathrm{HgCl}_{2}$ effect on MDCK junctional communication observed in this study is, moreover, supported by the results of Noguchi et al., who demonstrated that renal-specific toxicants do alter the GJIC function of MDCK cells (Noguchi et al., 1998).

Concerning the mechanism responsible for the $\mathrm{HgCl}_{2}$ induced down-modulation of MDCK junctional permeability, the present results seem to suggest that it may be a consequence of the $\mathrm{HgCl}_{2}$-induced changes in the antioxidant status of MDCK cells. It is well known how active oxygen species may (directly or indirectly) hamper the cellular capacity to establish functional gap junctions (Saez et al., 1993).

Taken together, our data indicate that: (i) the MDCK cell line is a very sensitive in vitro system, suitable for mechanistic studies on mercury-induced tubular cell injury; (ii) $\mathrm{Hg}$-induced alterations in the antioxidant cell defences (GSH cellular content and Gpx activity, in particular) may really play a pivotal role in the nephrotoxic potency of the metal; (iii) GJIC is a very sensitive and specific functional marker of $\mathrm{Hg}$ adverse effect of MDCK cells.

Further studies are currently being carried out by our group, in order to better investigate the mechanism(s) of $\mathrm{HgCl}_{2}$-induced inhibition of MDCK cell GJIC and the role that the observed alterations in the antioxidant cell defences may play to this concern.

\section{Acknowledgements}

We wish to thank Dr. Nadia Losio (Istituto Zooprofilattico Sperimentale della Lombardia e dell'Emilia
Romagna, Italy) for providing the MDCK cell line and for the fruitful discussion on cytotoxicity data; we also are indebted to Dr. Francesca Rovetta for helping with the manuscript preparation and to Mrs. Jennifer Boniotti for her skilled technical assistance. This work was financially supported by grants from the Italian Ministry of University and Scientific and Technological Research (MURST-Cofin. 1998) (to G.M.), from the "Centro di Studi per la Prevenzione degli Effetti Biologici Causati da Inquinanti Ambientali e Occupazionali" (Ente Universitario Lombardia Orientale, E.U.L.O.) (to G.M.), and by funds of the University of Brescia (to M.F.A.).

\section{References}

Aebi, H., 1984. Catalase in vitro. Methods in Enzymology 105, 121126.

Agency for Toxic Substance and Disease Registry, 1999. Toxicological Profile for Mercury. US Department of Health and Human Services, Public Health Service, Agency for Toxic Substance and Disease Registry, Bethesda, MD (publication no. TP-93/10).

Aleo, M.D., Taub, M.L., Kostyniak, P.J., 1992. Primary cultures of rabbit renal proximal tubule cells: III. Comparative cytotoxicity of inorganic and organic mercury. Toxicology and Applied Pharmacology 112, 312-317.

Ambudkar, I.S., Smith, M.W., Phelps, P.C., Regec, A.L., Trump, B.F., 1988. Extracellular $\mathrm{Ca}^{2+}$-dependent elevation in cytosolic $\mathrm{Ca}^{2+}$ potentiates $\mathrm{HgCl}_{2}$-induced renal proximal tubular cell damage. Toxicology and Industrial Health 4, 107-123.

Anderson, M.E., 1985. Determination of glutathione and glutathione disulfide in biological samples. Methods in Enzymology 113, 548555.

Ballatori, N., 1991. Mechanisms of metal transport across liver cell plasma membranes. Drug Metabolism Reviews 23, 83-132.

Ballatori, N., 1994. Glutathione mercaptides as transport forms of metals. Advances in Pharmacology 27, 271-298.

Berthoud, V.M., Ledbetter, M.L., Hertzberg, E.L., Saez, J.C., 1992. Connexin43 in MDCK cells: regulation by a tumor-promoting phorbol ester and Ca2 + European Journal of Cell Biology 57, 4050 .

Bohets, H.H., Van Thielen, M.N., Van Der Biest, I., Van Landeghem, G.F., D'Haese, P.C., Nouwen, E.J., De Broe, M.E., Dierickx, P.J., 1995. Cytotoxicity of mercury compounds in LLC-PK 1, MDCK and human proximal tubular cells. Kidney International 47, 395403.

Bradford, M.M., 1976. A rapid and sensitive method for quantitation of microgram quantities of proteins utilizing the principle of protein-dye binding. Analytical Biochemistry 72, 248-254.

Bruzzone, R., White, T.W., Paul, D.L., 1996. Connections with connexins: the molecular basis of direct intercellular signaling. European Journal of Biochemistry 238, 1-27.

Chavez, E., Holguin, J.A., 1988. Mitochondrial calcium release induced by $\mathrm{Hg}^{2+}$. Journal of Biological Chemistry 283, 3582-3587.

Divine, K.K., Ayala-Fierro, F., Barber, D.S., Carter, D.E., 1999. Glutathione, albumin, cysteine, and cys-gly effects on toxicity and accumulation of mercuric chloride in $\mathrm{LLC}^{-\mathrm{PK}_{1}}$ cells. Journal of Toxicology and Environmental Health 57, 489-505.

Elliget, K.A., Phelps, P.C., Trump, B.F., 1991. $\mathrm{HgCl}_{2}$-induced alteration of actin filaments in cultured primary rat proximal tubule epithelial cells labelled with fluorescein phalloidin. Cell Biology and Toxicology 7, 263-280.

Guo, R., Liu, L., Barajas, L., 1998. RT-PCR study of the distribution of connexin 43 mRNA in the glomerulus and renal tubular segments. American Journal of Physiology 275, R439- 47. 
Hua, J., Brun, A., Berlin, M., 1995. Pathological changes in the Brown Norway rat cerebellum after mercury vapour exposure. Toxicology 104, 83-90.

Lash, L.H., Zalups, R.K., 1992. Mercuric chloride-induced cytotoxicity and compensatory hypertrophy in rat kidney proximal tubular cells. Journal of Pharmacology and Experimental Therapeutics 261, 819-829.

Loch-Caruso, R., Corcos, I.A., Trosko, J.E., 1991. Inhibition of metabolic coupling by metals. Journal of Toxicology and Environmental Health 32, 33-48.

Lund, B.-O., Miller, D.M., Wood, J.S., 1993. Studies on $\mathrm{Hg}$ (II)induced $\mathrm{H}_{2} \mathrm{O}_{2}$ formation and oxidative stress in vivo and in vitro in rat kidney mitochondria. Biochemical Pharmacology 45, 2017-2024.

Madsen, K.M., Hansen, J.C., 1980. Subcellular distribution of mercury in the rat kidney cortex after exposure to mercuric chloride. Toxicology and Applied Pharmacology 54, 443-453.

Mazzoleni, G., Telo, P., Camplani, A., Tanganelli, S., Monarca, S., Ragnotti, G., 1994. Influence of the herbicide Linuron on growth rate and gap-junctional intercellular communication of cultured endothelial cells. Journal of Environmental Pathology, Toxicology and Oncology 13, 1-10.

Mazzoleni, G., Camplani, A., Telo, P., Pozzi, A., Tanganelli, S., Elfgang, C., Willecke, K., Ragnotti, G., 1996. Effect of tumor-promoting and anti-promoting chemicals on the viability and junctional coupling of human HeLa cells transfected with DNAs coding for various murine connexin proteins. Comparative Biochemistry and Physiology Part C Pharmacology, 247-256.

Miura, K., Clarkson, T.W., 1993. Reduced methylmercury accumulation in a methylmercury-resistant rat pheocromocitoma PC12 cell line. Toxicology and Applied Pharmacology 118, 39-45.

Morrison, A.R., Pascoe, N., 1986. Modification of renal cortical subcellular membrane phospholipids induced by mercuric chloride. Kidney International 29, 496-501.

Nath, K.A., Croatt, A.J., Likely, S., Behrens, T.W., Warden, D., 1996. Renal oxidant injury and oxidant response induced by mercury. Kidney International 50, 1032-1043.

Noguchi, M., Nomata, K., Watanabe, J., Kanetake, H., Saito, Y., 1998. Changes in the gap junctional intercellular communication in renal tubular epithelial cells in vitro treated with renal carcinogens. Cancer Letters 122, 77-84.
Oyama, Y., Nakata, M., Sakamoto, M., Chikahisa, L., Miyoshi, N., Satoh, M., 1998. Methylmercury toxicity in dissociated rat brain neurons: modification by L-cysteine and trimethylbenzylmercaptan and comparison with dimethylmercury and $\mathrm{N}$-ethylmaleimide. Environmental Toxicology and Pharmacology 4, 221-227.

Prozialeck, W.C., Lamar, P.C., 1998. Comparison of the Cytotoxic effects of cadmium $\left(\mathrm{Cd}^{2+}\right)$ in high and low resistance strains of MDCK cells that express different levels of E-cadherin. Toxicology in Vitro 12, 633-647.

Saez, J.C., Berthoud, V.M., Moreno, A.P., Spray, D.C., 1993. Gap junctions. Multiplicity of controls in differentiated and undifferentiated cells and possible functional implications. Advances in Second Messenger and Phosphoprotein Research 27, 163-198.

Sarafian, T., Anthony Verity, M., 1991. Oxidative mechanisms underlying methyl mercury neurotoxicity. Journal of International Developmental Neuroscience 9, 147-153.

Swierenga, S.H., Yamasaki, H., 1992. Performance of tests for cell transformation and gap-junction intercellular communication for detecting nongenotoxic carcinogenic activity. In: Mechanism of Carcinogenesis in Risk Identification. IARC Scientific Publications No. 116, pp. 165 193. International Agency for Research on Cancer, Lyon.

Tanaka, T., Naganuma, A., Imura, N., 1990. Role of $\gamma$-glutamyltranspeptidase in renal uptake and toxicity of inorganic mercury in mice. Toxicology 60, 187-198.

Valentine, J.S., Wertz, D.L., Lyons, T.J., Liou, L-L., Goto, J.J., Gralla, E.B., 1998. The dark side of dioxygen biochemistry. Current Opinion in Chemical Biology 2, 253-262.

Weinberg, J.M., Harding, P.G., Humes, H.D., 1982. Mitochondrial bioenergetics during the initiation of mercuric chloride-induced renal injury. I. Direct effects of in vitro mercuric chloride on renal cortical mitochondrial function. Journal of Biological Chemistry 257, 60-67.

Zalups, R.K., 2000. Molecular interactions with mercury in the kidney. Pharmacological Reviews 52, 113-144.

Zalups, R.K., Lash, L.H., 1990. Effects of uninephrectomy and mercuric chloride on renal gluthatione homeostasis. Journal of Pharmacology and Experimental Therapeutics 254, 962-970.

Zalups, R.K., Lash, L.H., 1994. Advances in understanding the renal transport and toxicity of mercury. Journal of Toxicology and Environmental Health 42, 1-44. 